University of Nebraska - Lincoln

DigitalCommons@University of Nebraska - Lincoln

USDA Wildlife Services - Staff Publications

U.S. Department of Agriculture: Animal and Plant Health Inspection Service

$1-1-2021$

\title{
Social identity and acceptability of wild pig (Sus scrofa) control actions: A case study of Texas hunters
}

\author{
Lauren Jaebker \\ Colorado State University, lauren.jaebker@colostate.edu \\ Tara L. Teel \\ Warner College of Natural Resources \\ Alan D. Bright \\ Warner College of Natural Resources \\ Hailey E. McLean \\ Warner College of Natural Resources \\ John M. Tomeček \\ Texas A\&M University \\ Follow this and additional works at: https://digitalcommons.unl.edu/icwdm_usdanwrc \\ Part of the Natural Resources and Conservation Commons, Natural Resources Management and \\ Seficyextpage for additional authorst \\ Population Biology Commons, Terrestrial and Aquatic Ecology Commons, Veterinary Infectious Diseases \\ Commons, Veterinary Microbiology and Immunobiology Commons, Veterinary Preventive Medicine, \\ Epidemiology, and Public Health Commons, and the Zoology Commons
}

Jaebker, Lauren; Teel, Tara L.; Bright, Alan D.; McLean, Hailey E.; Tomeček, John M.; Frank, Maureen G.; Connally, Rachael L.; Shwiff, Stephanie A.; and Carlisle, Keith M., "Social identity and acceptability of wild pig (Sus scrofa) control actions: A case study of Texas hunters" (2021). USDA Wildlife Services - Staff Publications. 2503.

https://digitalcommons.unl.edu/icwdm_usdanwrc/2503

This Article is brought to you for free and open access by the U.S. Department of Agriculture: Animal and Plant Health Inspection Service at DigitalCommons@University of Nebraska - Lincoln. It has been accepted for inclusion in USDA Wildlife Services - Staff Publications by an authorized administrator of DigitalCommons@University of Nebraska - Lincoln. 


\section{Authors}

Lauren Jaebker, Tara L. Teel, Alan D. Bright, Hailey E. McLean, John M. Tomeček, Maureen G. Frank, Rachael L. Connally, Stephanie A. Shwiff, and Keith M. Carlisle 


\title{
Social identity and acceptability of wild pig (Sus scrofa) control actions: A case study of Texas hunters
}

\author{
Lauren M. Jaebker ${ }^{a, b}$, Tara L. Teel ${ }^{a}$, Alan D. Bright ${ }^{a}$, Hailey E. McLean (D) ${ }^{a, b}$, \\ John M. Tomečekc, Maureen G. Frank ${ }^{c}$, Rachael L. Connallyc, Stephanie A. Shwiff ${ }^{b}$, and \\ Keith M. Carlisle (iD) ${ }^{\mathrm{a}, \mathrm{b}}$

\begin{abstract}
aDepartment of Human Dimensions of Natural Resources, Warner College of Natural Resources, Colorado State University, Fort Collins, Colorado, USA; ${ }^{b}$ National Wildlife Research Center, United States Department of Agriculture, Animal and Plant Health Inspection Service, Wildlife Services, Fort Collins, Colorado, USA; 'Department of Rangeland, Wildlife, and Fisheries Management, Texas A\&M University, College Station, Texas, USA
\end{abstract}

\begin{abstract}
Wild pigs (Sus scrofa) pose significant challenges to wildlife managers. This research explored Texas hunters' acceptability of wild pig control actions, and whether acceptability varied according to hunters' affiliation with four different categories of natural resource organizations as an indicator of social identity. Results of a survey $(n=37,317)$ revealed that most hunters were accepting of all control actions except toxicants and non-lethal deterrents. Mean acceptability scores for each action differed significantly across the four affiliation categories, but effect sizes were minimal. Hunters affiliated with agricultural organizations were the most accepting of control actions, while hunters with no organizational affiliations were least accepting. Findings suggested that while the type of organization with which a hunter affiliates provides some basis for predicting acceptability of control actions, the association is likely not significant enough to warrant differentiating wild pig outreach messaging on the basis of affiliation.
\end{abstract}

\section{KEYWORDS}

Feral pigs; attitudes; acceptability; social identity; hunters

\section{Introduction}

Wild pigs (Sus scrofa) epitomize a complex social and ecological issue of critical importance to wildlife management. Also known as feral swine, feral hogs, and wild boar (Keiter et al., 2016), wild pigs have been labeled as one of the top 100 most destructive invasive species in the world by the International Union for Conservation of Nature (Lowe et al., 2000). This includes causing an estimated 4.9 million metric tons of $\mathrm{CO}_{2}$ per year from wild pigs (O'Bryan et al., 2021). First introduced in the United States by Spanish explorers in the $16^{\text {th }}$ century, wild pigs have become established in 35 states with an estimated population size of at least 6 million individuals (Corn \& Jordan, 2017; Goedbloed et al., 2013; Mayer \& Brisbin, 2008). Due to high reproductive rates and the ability to easily adapt to new areas, establishment of new populations only takes a few individuals (Bevins et al., 2014). They also have been recognized as contributors to the transmission of parasites, viruses, and bacteria, which pose severe risks to humans, domestic livestock, and other wildlife (Brown et al., 
2019). Diseases of concern include trichinella, hepatitis E, pseudorabies, brucellosis, and influenza A (Bevins et al., 2014). Wild pigs cause considerable damage to agriculture, native flora and fauna, property, and cultural sites ("USDA-APHIS," 2016; Anderson et al., 2016; McKee et al., 2020). Pimental (2007) estimated that wild pigs cause the United States an estimated \$1.5 billion a year in crop losses and control costs, not including important categories like livestock losses and property damage. Actual losses, however, are likely much larger due to continued population growth of wild pigs in the United States, and inflation.

Different human behaviors can exacerbate or alleviate wild pig problems. For example, research suggests that a driving force of wild pig population expansion is human-mediated movement of these animals for the purpose of sport hunting (Grady et al., 2019; Hernández et al., 2018). The control of wild pig populations is inextricably tied to human behavior, given that it requires participation and cooperation among various stakeholder groups to reduce or limit the spread of these populations. Understanding the factors that inhibit or promote such behaviors is key to addressing this issue.

Several federal, state, and private entities have developed lethal and non-lethal methods to control wild pig populations and reduce their associated impacts. Lethal methods (e.g., sharpshooting, toxicants) aim to reduce the wild pig population size, whereas non-lethal methods (e.g., contraception and deterrents) intend to reduce damage without causing direct harm to the animals (Liordos et al., 2017). Management of wild pigs is controversial and involves conflicts among stakeholders and wildlife agencies, who may have differing attitudes toward the topic, often creating a barrier to effectively addressing the problem (Carlisle et al., 2020; Colvin et al., 2015; Daniels \& Walker, 2001; Keuling et al., 2016). For example, hunters and farmers hold negative attitudes toward wild pigs (Harper et al., 2016; McLean et al., 2021), suggesting less tolerance of the species and a desire for elimination that may not be widely accepted among the broader public. While McLean et al. (2021) found largely negative attitudes among Texas hunters toward wild pigs and relatively low levels of tolerance, their opinions about preferred population size of wild pigs were not consistent, suggesting that not all hunters support eradication. Wildlife managers are faced with increasing challenges to develop wild pig control techniques that are both ecologically sound and cost-effective, and socially acceptable to various publics (Heneghan \& Morse, 2019).

Literature on public acceptability of management plans and control actions for various native species has included gray wolves (Canis lupus), black bears (Ursus americanus), coyotes (Canis latrans), and white-tailed deer (Odocoileus virginianus) (Heneghan \& Morse, 2019; Sponarski et al., 2015; Urbanek et al., 2012; Vaske et al., 2013). Less attention, however, has been devoted to studying acceptability of control actions for exotic and/or invasive species (Koichi et al., 2013). Much of the existing social science research on wildlife-related issues has focused on individual attitudes, while neglecting to capture broader (e.g., group-level) perceptions and influences that can be a powerful driver of an individual's response to control actions (Van Eeden et al., 2019). Some research has shown, for example, that an individual's identification with a group can affect how they perceive the acceptability of wildlife management techniques (Heeren et al., 2017; Lute \& Gore, 2014; Naughton-Treves et al., 2003).

Given the role of human perceptions and behaviors in affecting the abundance and range of wild pigs, and the success of long-term solutions to their management, social science can contribute in this area (Baruch-Mordo et al., 2009). By understanding hunter acceptability 
of control strategies and the factors that influence acceptability for invasive species such as wild pigs, managers will be better equipped to predict whether social conflict over the use of a given strategy is likely to occur. To contribute to this understanding and address gaps in the literature, we investigated hunters' acceptability of wild pig control methods and applied a social identity approach to determine whether group-level factors can help predict hunters' acceptability of such actions.

\section{Social Identity Approach}

The social identity approach combines both social identity theory (Tajfel, 1978) and selfcategorization theory (Turner et al., 1987). This combination of theoretical foundations offers a useful framework for understanding inter-group conflicts (Abrams \& Hogg, 2010; Hornsey, 2008; Van Eeden et al., 2019). Social identity is defined as "that part of the individual's self-concept which derives from their knowledge of their membership of a social group (or groups) together with the value and emotional significance of that membership" (Tajfel, 1981, p. 255). Self-categorization can be explained as follows:

People self-categorize as belonging to different groups (e.g., gender, political affiliation, and ethnicity) and how they identify with these categorizations is both shaped by their personal values and attitudes and, in turn, shapes their attitudes, behaviors, beliefs, etc. as they seek to align with what they consider members of that group should do or think (Lute \& Gore, 2014, p. 5).

According to this approach, individuals assign themselves to groups to protect and reinforce their own self-identity. Group membership can boost individuals' self-esteem by providing social meaning and decreasing doubt about appropriate behavior, attitudes, and norms. This approach can also explain how groups form different values, beliefs, and attitudes (Van Eeden et al., 2020). Within a group, stereotypes are created about the "ideal" group member. These stereotypes provide standards and guidance for how individuals should behave, essentially driving the group members to become role models and act in accordance with group norms (Hornsey, 2008; Tajfel et al., 1979; Van Eeden et al., 2019). Individuals who do not conform to a group's values, attitudes, and norms belong to out-groups (Lute \& Gore, 2014).

Research in social identity theory suggests that individuals who affiliate with a particular group often have similar attitudes and preferences regarding an object or action of common interest. In the wildlife context, studies have found that attitudes toward control actions vary based on social identity or group affiliation (Bruskotter et al., 2009; Hornsey, 2008; Tajfel, 2010; Van Eeden et al., 2019). For example, Van Eeden et al. (2019) used a social identity approach to explain variation in perceptions of lethal and non-lethal control techniques among individuals who identified as animal rights activists, wildlife conservationists, and farmers in Australia for four animals (kangaroos, wild horses, dingoes, red foxes). We add to this literature by exploring the influence of group-level factors on wild pig control preferences among hunters in Texas.

\section{Importance of Research and Study Objectives}

We drew upon social identity theory and prior research to explore whether affiliation with different organizational groups affects hunters' acceptability of wild pig control actions in Texas. Hunters are important stakeholders in this context because they play a unique role in 
both the control and range expansion of wild pigs in the United States. Despite declines in hunting participation in the United States (Decker et al., 2017), hunters continue to exert influence on wildlife policy (Waldron et al., 2013). For example, the influence of Texas hunters was apparent when the Texas Agriculture Commissioner approved limited use of a wild pig toxicant in February 2017, following registration with the United States Environmental Protection Agency earlier that year. Less than a day after the Commissioner's announcement, the Texas Hog Hunters Association started an online petition opposing the toxicant, and within a week, the petition had almost 2,500 signatures. They opposed the toxicant because they believed it to be unsafe, causing harm to humans, wildlife, and the ecosystem. Wild pig hunting groups also joined forces with environmental, meat processing, and animal welfare groups to lobby the Texas Legislature. On April 10, 2017, the Texas House of Representatives passed a bill requiring further study of any toxicant prior to its use.

Texas is important for exploring the social aspects of wild pig management for several reasons. First, Texas has the largest population of wild pigs in the United States, with an estimated 2.5 million wild pigs as of 2013 (Lewis et al., 2019). Second, a 2014 study showed that $\$ 190$ million worth of crop production was lost in 11 states due to wild pig damage, with Texas suffering the greatest losses (Anderson et al., 2016). Third, Texas producers lost an additional $\$ 116$ million in 2018 from damage to four crop types by wild pigs (McKee et al., 2020). These studies demonstrate the magnitude of economic and agricultural impacts from wild pigs in Texas, where wild pigs are officially present in all but one county (Anderson et al., 2016; McKee et al., 2020).

Specific research objectives for this article were to determine: (1) Texas hunters' overall acceptability of different lethal and non-lethal control actions for wild pigs; and (2) whether acceptability varied by hunters' self-identified affiliation with different groups, namely different categories of natural resource organizations (i.e., agriculture, hunting, conservation). We treated organizational affiliation as an indicator of social identity, recognizing that individuals often choose to become members of groups that they feel share similar values and interests. This aligns with the basic definition of social identity (i.e., a person's sense of who they are based on their group memberships) (Tajfel, 1981). By regarding organizational affiliation as an indicator, or proxy, of social identity, we acknowledge in our approach that other factors (e.g., strength of affiliation, perception of shared values or norms of the group) can play a role in defining one's social identity that would be worth exploring in future research. We return to this point in the discussion. Our research was intended to ultimately inform hunter outreach strategies pursued by natural resource agencies and other organizations to garner greater stakeholder support for wild pig control efforts. If variation in levels of support exist, our findings would provide a basis for managers to develop targeted information and outreach materials for these organizations. For example, managers interested in building support for the use of a toxicant could prioritize engagement with organizations whose members exhibit lower levels of support for toxicant usage. In terms of theoretical contributions, we are not aware of any previous studies that have explored social identity theory, or a derivation of it, in the context of hunters and wild pig control methods in the United States. 


\section{Methods}

\section{Sampling and Data Collection}

Data for this article were collected through a self-reported questionnaire administered through Qualtrics under the auspice of the Texas A\&M AgriLife Extension Service. The sample was provided by the Texas Parks and Wildlife Department (TPWD) and consisted of every resident and nonresident Texas hunting license holder for the 2018-2019 hunting year who had an e-mail address on record with the agency $(n=169,619)$. All individuals in the sample were contacted by e-mail, including one initial contact on July 4 , 2019, and two reminder e-mails on July 9 and 10, 2019. The survey closed on August 12, 2019. The survey instrument and administration procedures were approved for use with human subjects through Texas A\&M University (IRB reference \#083112).

\section{Measurement of Key Concepts}

\section{Acceptability of Control Actions}

Attitudes are defined as an evaluation of an object as favorable or unfavorable (Fishbein \& Ajzen, 2011). We examined attitudes toward wild pig control actions as the object by asking hunters to rate their acceptability on a five-point scale $(1=$ completely unacceptable through $5=$ completely acceptable). A total of 10 wild pig control actions were included. Nine of those were lethal control actions (trap and kill, trap and sell, use of a toxicant, use of dogs, use of snares, lease hunting, owner/employee hunting, government or agency hunting, and aerial shooting), and one was a non-lethal method (use of deterrents [i.e., repellents]). Trap and sell involves the use of traps to capture and sell wild pigs (e.g., for meat processing). Owner/employee hunting occurs by a landowner or their employee to control wild pigs on the landowner's property. Government or agency hunting occurs by state or federal government employees to control wild pigs on public land or on private land with a landowner's permission. Trap and sell and use of dogs were included in the lethal category because the preponderance of their use involves lethal action (Kinsey, 2020).

\section{Organizational Affiliation}

For organizational affiliation, we asked participant hunters to select which wildlife, environmental, or agricultural organizations to which they belong, from 29 options (yes or no), including "none" (Table 1). Participants were also provided a write-in option to list any other organizations to which they belong. Organizations were identified for inclusion on the survey through an iterative process among professionals within the Texas A\&M AgriLife Extension Service engaged in agriculture, wildlife management, and natural resources conservation. The goal of this process was to identify organizations that represent the broadest group of individuals potentially interested or involved in wild pig issues, without excessive duplication. The resulting list was then checked with other professionals from within the Texas A\&M AgriLife Extension Service to determine if any significant gaps existed. We assigned all organizations to one of three categories (i.e., hunting, conservation, agriculture) based on the main purpose/objective presented in the given organization's mission statement. For example, we assigned The Nature Conservancy to the conservation category because their mission is "to conserve the lands and waters on which all life depends" (The Nature Conservancy, 2020). We recognize that some organizations could 
Table 1. Organization affiliation \& categorization.

\begin{tabular}{ll}
\hline Organization Affiliation & Category (i.e., hunting, conservation, or agriculture) \\
\hline Texas Farm Bureau & Agriculture \\
Texas Southwestern Cattle Raisers & Agriculture \\
Texas Sheep and Goat Raisers Association & Agriculture \\
Texas Pecan Growers & Agriculture \\
Texas Cotton Association & Agriculture \\
Quail Forever & Hunting \\
Ducks Unlimited & Hunting \\
Texas Trophy Hunters Association & Hunting \\
Pheasants Forever & Hunting \\
Texas Deer Association & Hunting \\
Houston Safari Club & Hunting \\
Backcountry Hunters and Anglers & Hunting \\
Safari Club International & Hunting \\
Rocky Mountain Elk Foundation & Hunting \\
Texas Hog Hunters Association & Hunting \\
National Turkey Federation & Hunting \\
Texas Dove Hunters Association & Hunting \\
Dallas Safari Club & Hunting \\
Exotic Wildlife Association & Conservation \\
Audubon Society & Conservation \\
Texas Master Naturalist & Conservation \\
The Nature Conservancy & Conservation \\
Texas Land Conservancy & Conservation \\
Texas Forestry Association & Conservation \\
Coastal Conservation Association & Conservation \\
\hline & \\
\hline
\end{tabular}

belong in more than one distinct category. However, based on the study objectives, one category was chosen for simplicity and ease of analysis. Our approach was further supported by exploratory analysis in the early stages of our research, which consisted of a two-step process. We conducted K-means cluster analysis to determine if any meaningful groups emerged from responses for the full suite of organizations included on the survey that could help guide our classification scheme. We then performed one-way analysis of variance (ANOVA) tests to determine if resulting clusters significantly differed in their acceptability of wild pig management actions. Results of these exploratory procedures did not reveal any conceptually meaningful groupings or patterns in management preferences across respondent segments that would warrant a different approach. We therefore chose to keep our conceptually defined categories of hunting, agriculture, and conservation for final analysis.

Prior to analysis, organizational affiliation variables were collapsed into four dummy variables: (1) affiliation with only agriculture groups, (2) affiliation with only hunting groups, (3) affiliation with only conservation groups, and (4) affiliation with no groups, or none. Respondents who indicated they identified with more than one of the three categories, from the pre-determined list, were dropped from further analysis in the interest of examining distinct differences among groups, rather than the combination of groups. Criteria for inclusion of organizations in our analyses, for both fixed and open-ended response options, were $n>100$ responses. Responses for the open-ended "other" category provided over 100 new organizations. However, in the interest of making the data more manageable, we selected only the first organization that a respondent listed, under the assumption that this organization was likely most salient to them. From these responses, Backcountry Hunters and Anglers, Safari Club International, Rocky Mountain Elk Foundation, and Coastal Conservation Association met our criterion of $n>100$ and were therefore included 
in the final analysis. Multiple coauthors were involved in the coding process for determining assignment of organizations into categories, allowing for more input on the final classification scheme. After applying these criteria, the agriculture category included a total of five organizations, hunting consisted of 13 organizations, and conservation consisted of seven organizations (Table 1).

\section{Data Analysis}

We conducted descriptive analyses (e.g., frequencies) to explore the overall acceptability of control actions (objective 1), and one-way ANOVA with Tamhane's (used due to unequal variances) post-hoc tests to explore differences in acceptability of control actions across organizational categories (objective 2). We used an alpha level of $p<.05$ to indicate statistical significance for all analyses. We calculated effect size measures (eta) as an indicator of practical significance, in part due to the increased chance of finding statistical significance with large sample sizes. We used criteria specified in the literature to denote minimal, typical, and substantial effects (eta > .10, .24, .37, respectively) (Cohen, 1988; Vaske, 2019).

\section{Results}

Of the 169,619 surveys administered, 10,199 were undelivered, and 37,317 were returned, resulting in a $23 \%$ response rate. Respondents were almost exclusively male (96\%), predominately white (91\%), and $89 \%$ were Texas residents. Mean age was 52, and median age was 53. A bachelor's degree was the most common level of highest educational achievement, and most respondents (65\%) had household income more than $\$ 100,000$ per year. Regarding the representativeness of the study population, we obtained information from TPWD that showed the mean age of licensed Texas hunters is $51.5,89 \%$ were male, and $94 \%$ were Texas residents. Compared to this information, our study had a somewhat higher proportion of males and out-of-state residents. Seventy-three percent of respondents reported they had hunted wild pigs. Of the remaining respondents in the analysis $(61 \%$, $n=22,612$ ) following our classification procedures described above, approximately $26 \%$, $n=5,824$ solely identified with hunting organizations; $20 \%, n=4,508$ solely identified with agricultural organizations, $7 \%, n=1,671$ solely identified with conservation organizations and $47 \%, n=10,609$ identified with none of the organizations.

\section{Objective 1: Acceptability of Control Actions}

All control actions were considered acceptable by most hunters except the use of toxicants and non-lethal deterrents. For example, descriptive statistical analysis (Table 2; Figure 1) indicated that only about $3 \%$ of respondents believed it to be unacceptable to trap and lethally remove wild pigs, whereas about $71 \%$ believed it to be acceptable. Aerial shooting was unacceptable to only about $6 \%$ of respondents, whereas $60 \%$ found it to be acceptable. Use of a toxicant was unacceptable to $27 \%$, whereas $32 \%$ found this action to be acceptable, and $18 \%$ were neutral regarding this type of action. The use of non-lethal deterrents was acceptable by $30 \%$ of respondents, whereas $22 \%$ found it to be unacceptable. 
Table 2. Descriptive percentages for the acceptability of control actions.

\begin{tabular}{|c|c|c|c|c|c|}
\hline Control Action $^{a}$ & $\begin{array}{c}\text { Completely } \\
\text { Unacceptable } \\
(\%)\end{array}$ & $\begin{array}{c}\text { Somewhat } \\
\text { Unacceptable } \\
(\%)\end{array}$ & $\begin{array}{l}\text { Neutral } \\
(\%)\end{array}$ & $\begin{array}{c}\text { Somewhat } \\
\text { Acceptable (\%) }\end{array}$ & $\begin{array}{c}\text { Completely } \\
\text { Acceptable (\%) }\end{array}$ \\
\hline $\begin{array}{l}\text { Trap and lethally } \\
\text { remove }\end{array}$ & 3 & 3 & 8 & 15 & 71 \\
\hline Trap and sell & 6 & 5 & 13 & 17 & 59 \\
\hline Safe, humane toxicant & 27 & 13 & 18 & 11 & 32 \\
\hline Use of dogs & 9 & 9 & 18 & 18 & 46 \\
\hline Use of snares & 13 & 12 & 19 & 17 & 39 \\
\hline Non-lethal deterrents & 22 & 11 & 27 & 11 & 30 \\
\hline Lease hunting & 3 & 3 & 10 & 17 & 68 \\
\hline $\begin{array}{l}\text { Owner/employee } \\
\text { hunting }\end{array}$ & 1 & 1 & 7 & 15 & 76 \\
\hline $\begin{array}{l}\text { Government or agency } \\
\text { hunting }\end{array}$ & 16 & 8 & 18 & 15 & 43 \\
\hline Aerial shooting & 7 & 5 & 11 & 17 & 61 \\
\hline
\end{tabular}

${ }^{a}$ Control actions coded as (1) completely unacceptable, (2) somewhat unacceptable (3) neutral, (4) somewhat acceptable, and (5) completely acceptable.

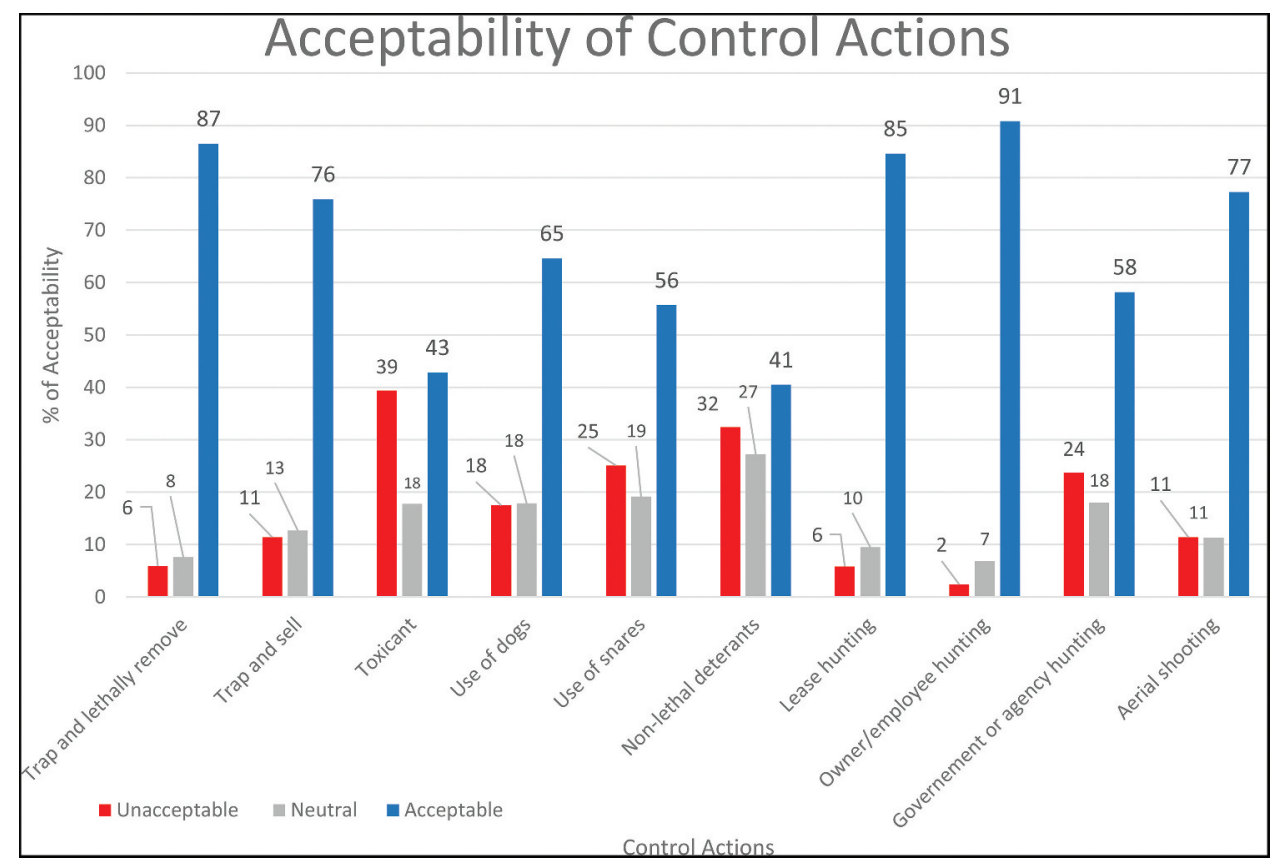

Figure 1. Percent acceptability of wild pig control actions. ${ }^{1}$

\section{Objective 2: Organizational Affiliation and Acceptability of Control Actions}

The ANOVAs revealed that mean acceptability scores for each of the 10 control actions differed significantly across organizational categories (Table 3). However, patterns of those differences varied by action. The hunting group was more supportive (than some or all the other groups) of certain actions, including trap and sell, snares, and toxicants. For example, the hunting category differed significantly $(p<.05)$ from the none category for the trap and 
Table 3. ANOVA results for comparing acceptability of control actions across social identity categories.

\begin{tabular}{|c|c|c|c|c|c|c|c|}
\hline Control Action $^{a}$ & $\begin{array}{c}\text { Agricultural } \\
\text { Only } \\
(n=5,824) \\
(26 \%)\end{array}$ & $\begin{array}{l}\text { Hunting } \\
\text { Only } \\
(n=4,508) \\
(20 \%)\end{array}$ & $\begin{array}{c}\text { Conservation } \\
\text { Only } \\
(n=1,671) \\
(7 \%)\end{array}$ & $\begin{array}{c}\text { None } \\
(n=10,609) \\
(47 \%)\end{array}$ & $F$-value & $p$-value & $\begin{array}{l}\text { Eta } \\
(\eta)\end{array}$ \\
\hline Trap and lethally remove & $4.52^{\mathrm{a}}$ & $4.59^{\mathrm{b}}$ & $4.58^{\mathrm{ab}}$ & $4.45^{c}$ & 28.172 & $<.001$ & .004 \\
\hline Trap and sell & $4.20^{\mathrm{a}}$ & $4.23^{\mathrm{ab}}$ & $4.24^{\mathrm{a}}$ & $4.16^{\mathrm{ac}}$ & 5.248 & .001 & $<.001$ \\
\hline Safe, humane toxicant & $3.03^{\mathrm{a}}$ & $3.44^{\mathrm{b}}$ & $3.18^{c}$ & $2.99^{\mathrm{a}}$ & 87.524 & $<.001$ & .012 \\
\hline Use of dogs & $3.97^{\mathrm{a}}$ & $3.88^{b}$ & $3.87^{\mathrm{bc}}$ & $3.79^{\mathrm{cd}}$ & 23.893 & $<.001$ & .003 \\
\hline Use of snares & $3.63^{\mathrm{a}}$ & $3.66^{\mathrm{ab}}$ & $3.54^{\mathrm{ac}}$ & $3.49^{c}$ & 18.053 & $<.001$ & .003 \\
\hline Non-lethal deterrents & $3.18^{a}$ & $3.07^{b}$ & $3.20^{\mathrm{a}}$ & $3.16^{\mathrm{a}}$ & 6.033 & $<.001$ & $<.001$ \\
\hline Lease hunting & $4.55^{\mathrm{a}}$ & $4.21^{\mathrm{b}}$ & $4.43^{c}$ & $4.48^{c}$ & 109.846 & $<.001$ & .015 \\
\hline Owner/employee hunting & $4.68^{\mathrm{a}}$ & $4.62^{b}$ & $4.70^{\mathrm{a}}$ & $4.63^{b}$ & 9.606 & $<.001$ & .001 \\
\hline $\begin{array}{l}\text { Government or agency } \\
\text { hunting }\end{array}$ & $3.62^{\mathrm{a}}$ & $3.44^{b}$ & $3.67^{\mathrm{a}}$ & $3.68^{\mathrm{a}}$ & 27.791 & $<.001$ & .004 \\
\hline Aerial shooting & $4.33^{\mathrm{a}}$ & $4.27^{\mathrm{ab}}$ & $4.19^{b c}$ & $4.11^{c}$ & 45.011 & $<.001$ & .006 \\
\hline
\end{tabular}

${ }^{a}$ Control actions coded as (1) completely unacceptable, (2) somewhat unacceptable (3) neutral, (4) somewhat acceptable, and (5) completely acceptable.

${ }^{\mathrm{b}}$ Means with different superscripts across each row are significantly different at $p<.05$ using Tamhane's post-hoc tests.

${ }^{\mathrm{c}}$ All values are statistically significant at $p<.001$.

sell method, with mean acceptability scores of 4.23 and 4.16, respectively, and the hunting category differed significantly from the conservation and the none categories for use of snares, with means of $3.66,3.54$, and 3.49 , respectively.

Individuals who identified with hunting groups were more accepting of the use of toxicants $(M=3.44)$ than individuals who affiliated with groups in the other categories we examined. The agriculture group was more supportive of snares $(M=3.63)$, use of dogs $(M=3.97)$, lease hunting $(M=4.55)$, and aerial shooting $(M=4.33)$ to control wild pigs than individuals from the other categories. For example, for the use of snares, agriculture differed significantly from none, with mean acceptability scores of 3.63 and 3.49, respectively. Individuals who belonged to a conservation group were more accepting of the use of trap and sell $(M=4.24)$, non-lethal deterrents $(M=3.20)$, and owner/employee hunting $(M=4.70)$ than members of the other identity groups.

Lease hunting varied between agricultural and hunting groups, with mean scores of 4.55 and 4.21, respectively. For owner and employee hunting, agriculture varied significantly from hunting and none categories, with mean acceptability scores of 4.68, 4.62, and 4.63, respectively. The hunting category significantly differed from all other groups on acceptance of government hunting, with a mean of 3.44. In terms of the lethal control actions, acceptability of aerial hunting differed among agricultural, hunting, and none categories, with means of $4.33,4.27$, and 4.11, respectively. For non-lethal deterrents, agricultural differed from hunting, with means of 3.18 and 3.07, respectively. Hunting differed from all other categories on this action, with a mean acceptability score of 3.07. Finally, of those individuals who did not affiliate with none of the groups, the only method found more acceptable compared to other groups was government or agency hunting $(\mathrm{M}=3.68)$. Although statistical differences were evident across categories, it is important to note that effect sizes for all comparisons (eta $=.001$ to .015$)$ indicated a less than minimal or small effect (Cohen, 1988; Vaske, 2019). 


\section{Discussion}

The objectives of this article were to examine the overall acceptability of methods for controlling wild pigs among Texas hunters and to determine whether acceptability of such actions varied among hunters who affiliated with different types of natural resource organizations (i.e., agricultural, conservation, hunting). Whereas some research has shown that hunters, as a group, tend to be more accepting of lethal control actions for human-wildlife conflict scenarios (Liordos et al., 2017), this article sought to determine whether there are multiple social groups with which hunters self-identify or affiliate that might explain differences in preferences for wild pig control actions. We found that all control actions were considered acceptable by most hunters except for the use of toxicants and non-lethal deterrents. These findings suggest that most hunters accept the need for wild pig control in Texas and would be supportive of most control actions. We also found differences in the acceptability of control actions across the categories of natural resource organizations we examined. Hunters who affiliated with agricultural organizations were the most accepting of the full suite of lethal and nonlethal actions for controlling wild pigs, which stands to reason given the extensive impacts of wild pigs on agriculture, whereas individuals who were not affiliated with any group were somewhat less accepting of these actions.

Like other studies that have examined stakeholder group identification in relation to acceptability of control actions in the context of other wildlife species (Bruskotter et al., 2009), our findings suggest that social identity-related factors (i.e., group-level influences) are associated with acceptability of control actions for wild pigs. However, the practical differences we detected among the organizational groups included in our study were small, and we propose several reasons why this may be the case. First, we measured organizational affiliation as an indicator or proxy of social identity, but we did not ask about strength of identity with the organizations in question. Survey items that measure strength of affiliation with organizations (e.g., 'how strongly do you identify with the norms of group X?') are warranted (Van Eeden et al., 2020). Hunters may have differing strengths of association with different organizations, and those organizations may also have differing levels of relevance or salience in terms of wild pig issues. Second, although overall membership in the different categories of organizations may explain differences in acceptability of wild pig control actions, we examined a subset of that membership, hunters, whose preferences we found to be relatively homogenous. For example, there was little variability among Texas hunters' acceptance of most control methods, which may help to explain why effect sizes were small. Third, there might be variability among individual groups in their attitudes, beliefs, and norms relative to wild pig management that is not adequately captured when assigning groups to broad categories as we did in our analysis. Finally, group-level influences may be of less consequence in this specific wildlife context, demanding that other potential predictors be explored in future research. Indeed, attitudes toward wildlife-related issues are shaped by an array of internal (e.g., values) and external (e.g., cultural, institutional) influences (Van Eeden et al., 2020) that can affect future outcomes for management practices (Lischka et al., 2018; Van Eeden et al., 2020). Because we did not see meaningful variation across organizational categories, tailoring outreach materials specifically to hunters based on membership in these organizations may not be an effective strategy for natural resource managers - at least insofar 
as the objective is to influence hunters who are members of these organizations. Consistent messaging across categories may be more appropriate, instead of crafting different targeted messages.

This research should not be interpreted to mean that distinct social groups do not exist within the larger population of hunters, as we only considered hunters' self-identified affiliations with natural resource organizations. Other possible classification schemes could include groups defined by hunting motivations (Decker \& Connelly, 1989). For example, subsistence hunters, recreation/sport hunters, and trophy hunters, could all conceivably be distinct social groups with significantly different levels of acceptability for wildlife control actions. Further, it may have been possible to classify some of the organizations analyzed in this study under an alternative scheme (e.g., classified according to how their mission aligns with different hunting motivations), which may have yielded stronger or weaker support for organizational affiliation serving as a predictor of management practices.

This article contributes to the human dimensions of wildlife literature. Broadly, this study highlights the need for more research into group-level factors that influence wildlife management preferences; most scholarship in this area has focused on individual-level factors, like values and attitudes (Lischka et al., 2018; Manfredo et al., 2014). Our research, more specifically, adds a unique contribution to the growing literature on social identity theory and its application in wildlife management. Previous studies within natural resource-related fields have operationalized social identity through survey items asking participants to rate the extent to which they identify with identities of interest (e.g., Van Eeden et al., 2019, 2020). Our study took a different approach by exploring other possible indicators of identity - in this case, membership in different natural resource organizations. We applied this approach to examine factors that may affect hunters' acceptance of different methods for controlling wild pigs. Given that they are considered one of the world's most destructive invasive species (Lowe et al., 2000), greater attention to the human dimensions of wild pig management, and invasive species more generally, is warranted. Our findings specific to the hunting community add to this growing area of concern.

Findings and limitations of this study point to directions for future research. Examples of productive avenues for future research include exploring additional indicators of identity in the context of wild pig control preferences. Because roughly half of respondents did not claim membership in any of the organizations we analyzed, there may be alternative ways to segment hunters that should be explored. This also suggests there may be limitations in targeting the organizations we analyzed to reach hunters, given the large number in our study who were not affiliated with any of the organizations. Relatedly, for similar studies outside of Texas, it would likely be necessary to include different organizational affiliations as the number of organizations in our study were specific to Texas. While it was beyond the scope of this investigation, it could be valuable to examine the extent to which affiliation with multiple organization types (e.g., hunting and conservation) might affect acceptability of management actions. Future research is also needed to understand the wild pig-related attitudes and beliefs of non-hunters within the same organizations we analyzed. Last, given that our research was conducted with hunters in Texas, there is a need to investigate hunters' acceptance of wild pig control methods and how that acceptance may differ across hunter segments within other areas of the U.S. Such future research, together with the 
findings from this study, can improve wildlife management agencies' understanding of the role of group affiliation in shaping stakeholder perceptions of wild pigs and their management, which in turn can inform more successful outreach strategies.

\section{Note}

1. All control actions by percentages where 'somewhat unacceptable' was collapsed within the 'unacceptable' category. Similarly, 'somewhat acceptable' was collapsed within the 'acceptable' category, resulting in three new categories of either unacceptable, neutral, or acceptable.

\section{Acknowledgments}

We wish to thank the Texas A\&M University System, Texas A\&M AgriLife Extension Service, and Texas Wildlife Services for their support with the inception, funding, and delivery of this project. We also thank the United States Department of Agriculture, Animal and Plant Health Inspection Service, Wildlife Services, National Feral Swine Damage Management Program, and the National Wildlife Research Center for making this research possible. We specifically wish to thank Mr. Michael J. Bodenchuk for his insightful assistance during the formation of this study, and the Texas Parks and Wildlife Department for access to hunter licensee data. Additional support was provided by Colorado State University. The findings and conclusions in this publication are those of the authors and should not be constructed to represent any official State of Texas, Texas A\&M University System, USDA, or United States Government determination or policy.

\section{Funding}

This work was supported by Texas A\&M AgriLife Extension Service, College Station, TX, USA.

\section{Disclaimer}

The findings and conclusions in this publication are those of the authors and should not be construed to represent any official USDA, U.S. Government determination or policy, nor does it represent those of Texas A\&M AgriLife Extension Service, the Texas A\&M University System, or the State of Texas.

\section{ORCID}

Hailey E. McLean (D) http://orcid.org/0000-0002-3892-0334

Keith M. Carlisle (D) http://orcid.org/0000-0002-5205-1294

\section{References}

Abrams, D., \& Hogg, M. A. (2010). Social identity and self categorization. In J. F. Dovidio, M. Hewstone, P. Glick, \& V. M. Esses (Eds.), The Sage handbook of prejudice, stereotyping and discrimination (pp. 179-193). Sage.

Anderson, A., Slootmaker, C., Harper, E., Holderieath, J., \& Shwiff, S. A. (2016). Economic estimates of feral swine damage and control in 11 US states. Crop Protection, 89, 89-94. https://www. sciencedirect.com/science/article/abs/pii/S0261219416301557

Baruch-Mordo, S., Breck, S. W., Wilson, K. R., \& Broderick, J. (2009). A tool box half full: How social science can help solve human-wildlife conflict. Human Dimensions of Wildlife, 14(3), 219-223. https://doi.org/10.1080/10871200902839324 
Bevins, S. N., Pedersen, K., Lutman, M. W., Gidlewski, T., \& Deliberto, T. J. (2014). Consequences associated with the recent range expansion of nonnative feral swine. BioScience, 64(4), 291-299. https://doi.org/10.1093/biosci/biu015

Brown, V. R., Marlow, M. C., Maison, R. M., Gidlewski, T., Bowen, R., \& Bosco-Lauth, A. (2019). Current status and future recommendations for feral swine disease surveillance in the United States. Journal of Animal Science, 97(6), 2279-2282. https://doi.org/10.1093/jas/skz054

Bruskotter, J. T., Vaske, J. J., \& Schmidt, R. H. (2009). Social and cognitive correlates of Utah residents' acceptance of the lethal control of wolves. Human Dimensions of Wildlife, 14(2), 119-132. https://doi.org/10.1080/10871200802712571

Carlisle, K. M., Harper, E. E., \& Shwiff, S. A. (2020). An examination of ethical attitudes towards wild pig (Sus scrofa) toxicants in the United States. International Journal of Pest Management, 1-8. https://doi.org/10.1080/09670874.2020.1791372

Cohen, J. (1988). Statistical power analysis for the behavioral sciences (2 ed.). Lawrence Erlbaum Associates.

Colvin, R., Witt, G. B., \& Lacey, J. (2015). The social identity approach to understanding socio-political conflict in environmental and natural resources management. Global Environmental Change, 34, 237-246. https://doi.org/10.1016/j.gloenvcha.2015.07.011

Corn, J. L., \& Jordan, T. R. (2017). Development of the national feral swine map, 1982-2016. Wildife Society Bulletin, 41(4), 758-763. https://doi.org/10.1002/wsb.808

Daniels, S. E., \& Walker, G. B. (2001). Working through environmental conflict: The collaborative learning approach. Praeger Publishing.

Decker, D. J., \& Connelly, N. A. (1989). Motivations for deer hunting: Implications for antlerless deer harvest as a management tool. Wildlife Society Bulletin, 17(4), 455-463. https://www.jstor.org/ stable/pdf/3782713.pdfcasa_token=UyAwj353 JswAAAAA:m1yitzv5nFSw_ QYC8WFFiz2nz38RQWQM5JylDJOMfJkyLrI08vc_TCSzeFtqUhHkpu9elM8M14_ qOGlE8zgVtTJtm6dL8Q0j_pyFhZSq74sG4P7bOt7D

Decker, D. J., Organ, J. F., Forstchen, A. B., Jacobson, C. A., Siemer, W. F., Smith, C. A., Lederle, P. E., \& Schiavone, M. V. (2017). Wildlife governance in the 21st century-Will sustainable use endure? Wildlife Society Bulletin, 41(4), 821-826. https://doi.org/10.1002/wsb.830

Fishbein, M., \& Ajzen, I. (2011). Predicting and changing behavior: The reasoned action approach. Psychology Press (Taylor \& Francis).

Goedbloed, D. J., Megens, H. J., Van Hooft, P., Herrero-Medrano, J. M., Lutz, W., Alexandri, P., Crooijmans, R. P. M. A., Groenen, M., Van WIEREN, S. E., Ydenberg, R. C., \& Prins, H. H. T. (2013). Genome-wide single nucleotide polymorphism analysis reveals recent genetic introgression from domestic pigs into Northwest European wild boar populations. Molecular Ecology, 22(3), 856-866. https://doi.org/10.1111/j.1365-294X.2012.05670.x

Grady, M. J., Harper, E. E., Carlisle, K. M., Ernst, K. H., \& Shwiff, S. A. (2019). Assessing public support for restrictions on transport of invasive wild pigs (Sus scrofa) in the United States. Journal of Environmental Management, 237, 488-494. https://doi.org/10.1016/j.jenvman.2019.02. 107

Harper, E. E., Miller, C. A., Vaske, J. J., Mengak, M. T., \& Bruno, S. (2016). Stakeholder attitudes and beliefs toward wild pigs in Georgia and Illinois. Wildlife Society Bulletin, 40(2), 269-273. https:// doi.org/10.1002/wsb.653

Heeren, A., Karns, G., Bruskotter, J., Toman, E., Wilson, R., \& Szarek, H. (2017). Expert judgement and uncertainity regarding the protection of imperiled species. Conservation Biology, 31(3), 657-665. https://doi.org/10.1111/cobi.12838

Heneghan, M. D., \& Morse, W. C. (2019). Acceptability of management actions and the potential for conflict following human-black bear encounters. Society \& Natural Resources, 32(4), 434-451. https://doi.org/10.1080/08941920.2018.1556756

Hernández, F. A., Parker, B. M., Pylant, C. L., Smyser, T. J., Piaggio, A. J., Lance, S. L., Milleson, M. P., Austin, J. D., \& Wisely, S. M. (2018). Invasion ecology of wild pigs (Sus scrofa) in Florida, USA: The role of humans in the expansion and colonization of an invasive wild ungulate. Biological Invasions, 20(7), 1865-1880. https://doi.org/10.1007/s10530-018-1667-6 
Hornsey, M. J. (2008). Social identity theory and self-categorization theory: A historical review. Social and Personality Psychology Compass, 2(1), 204-222. https://doi.org/10.1111/j.1751-9004.2007. 00066.x

Keiter, D. A., Mayer, J. J., \& Beasley, J. C. (2016). What is in a "common" name? A call for consistent terminology for nonnative Sus scrofa. Wildlife Society Bulletin, 40(2), 384-387. https://doi.org/10. $1002 /$ wsb.649

Keuling, O., Strauß, E., \& Siebert, U. (2016). Regulating wild boar populations is "somebody else's problem"!-human dimension in wild boar management. Science of the Total Environment, 554, 311-319. https://doi.org/10.1016/j.scitotenv.2016.02.159

Kinsey, J. C. (2020). Ecology and management of wild pigs. Texas Parks and Wildlife Department. https://tpwd.texas.gov/publications/pwdpubs/media/pwd_bk_w7000_1943.pdf

Koichi, K., Cottrell, A., Sangha, K. K., \& Gordon, I. J. (2013). What determines the acceptability of wildlife control methods? A case of feral pig management in the Wet Tropics World Heritage Area, Australia. Human Dimensions of Wildlife, 18(2), 97-108. https://doi.org/10.1080/10871209.2013. 727523

Lewis, J. S., Corn, J. L., Mayer, J. J., Jordan, T. R., Farnsworth, M. L., Burdett, C. L., VerCauteren, K. C., Sweeney, S. J., \& Miller, R. S. (2019). Historical, current, and potential population size estimates of invasive wild pigs (Sus scrofa) in the United States. Biological Invasions, 21(7), 2373-2384. https://doi.org/10.1007/s10530-019-01983-1

Liordos, V., Kontsiotis, V. J., Georgari, M., Baltzi, K., \& Baltzi, I. (2017). Public acceptance of management methods under different human-wildlife conflict scenarios. Science of the Total Environment, 579, 685-693. https://doi.org/10.1016/j.scitotenv.2016.11.040

Lischka, S. A., Teel, T. L., Johnson, H. E., Reed, S. E., Breck, S., Carlos, A. D., \& Crooks, K. R. (2018). A conceptual model for the integration of social and ecological information to understand human-wildlife interactions. Biological Conservation, 225, 80-87. https://doi.org/10.1016/j.bio con.2018.06.020

Lowe, S., Browne, M., Boudjelas, S., \& De Poorter, M. (2000). 100 of the world's worst invasive alien species: A selection from the global invasive species database (Vol. 12). Invasive Species Specialist Group Auckland.

Lute, M. L., \& Gore, M. L. (2014). Stewardship as a path to cooperation? Exploring the role of identity in intergroup conflict among Michigan wolf stakeholders. Human Dimensions of Wildlife, 19(3), 267-279. https://doi.org/10.1080/10871209.2014.888600

Manfredo, M. J., Teel, T. L., Gavin, M., \& Fulton, D. (2014). Considerations in representing human individuals in social-ecological models. In M. J. Manfredo, J. J. Vaske, A. Rechkemmer, \& E. A. Duke (Eds.), Understanding society and natural resources: Forging new strands in integration across the social sciences. (pp. 137-158). Springer Press.

Mayer, J. J., \& Brisbin, I. L. (2008). Wild pigs in the United States: Their history, comparative morphology, and current status. University of Georgia Press.

McKee, S., Anderson, A., Carlisle, K., \& Shwiff, S. A. (2020). Economic estimates of invasive pig damage to crops in 12 US states. Crop Protection, 132(105105), 105105. https://doi.org/10.1016/j. cropro.2020.105105

McLean, H. E., Teel, T. L., Bright, A. D., Jaebker, L. M., Tomecek, J. M., Frank, M. G., ... Carlisle, K. M. (2021). Understanding tolerance for an invasive species: An investigation of hunter acceptance capacity for wild pigs (Sus scrofa) in Texas. Journal of Environmental Management, 285, 112143.Naughton-Treves, L., Grossberg, R., \& Treves, A. (2003). Paying for tolerance: Rural citizens' attitudes toward wolf depredation and compensation. Conservation Biology, 17(6), 1500-1511. https://doi.org/10.1016/j.jenvman.2021.112143

Naughton-Treves, L., Grossberg, R., \& Treves, A. (2003). Paying for tolerance: rural citizens' attitudes toward wolf depredation and compensation. Conservation biology, 17(6), 1500-1511.

O'Bryan, C. J., Patton, N. R., Hone, J., Lewis, J. S., Berdejo-Espinola, V., Risch, D. R., Holden, M. H., \& McDonald-Madden, E. (2021). Unrecognized threat to global soil carbon by a widespread invasive species. Global Change Biology, 00, 1-6. https://doi.org/10.1111/gcb.15769

Pimental, D. (2007). Environmental and economic costs of vertebrate species invasions into the United States. Managing Vertebrate Invasive Species. 38. 
Sponarski, C. C., Vaske, J. J., \& Bath, A. J. (2015). Differences in management action acceptability for coyotes in a National Park. Wildlife Society Bulletin, 39(2), 239-247. https://doi.org/10.1002/wsb. 535

Tajfel, H. (1978). The achievement of group differentiation. In H. Tajfel (Ed.), Differentiation between social groups: Studies in the social psychology of intergroup relations (pp. 77-98)). Academic Press.

Tajfel, H. (1981). Human groups and social categories: Studies in social psychology. Cup Archive.

Tajfel, H. (Ed.). (2010). Social identity and intergroup relations. Cambridge University Press.

Tajfel, H., Turner, J. C., Austin, W. G., \& Worchel, S. (1979). An integrative theory of intergroup conflict. In Organizational identity: A reader (pp. 56-65). (Eds.) The Social Psychology of Intergroup Relations, Monterey: Brooks Cole.

The Nature Conservancy. (2020). Retrieved July 23, 2020, from https://www.nature.org/en-us/aboutus/who-we-are/our-mission-vision-and-values/\#: :text=The $\% 20$ mission $\% 20$ of $\% 20$ The $\%$ 20Nature,needs\%20and\%20enrich\%20our\%20lives

Turner, J. C., Hogg, M. A., Oakes, P. J., Reicher, S. D., \& Wetherell, M. S. (1987). Rediscovering the social group: A self-categorization theory. Basil Blackwell.

United States Department of Agriculture Animal and Plant Health Inspection Service [USDAAPHIS]. (2016, April 6). Retrieved November 8, 2019, from. https://www.aphis.usda.gov/aphis/ ourfocus/wildlifedamage/operational-activities/feral-swine

Urbanek, R. E., Nielsen, C. K., Davenport, M. A., \& Woodson, B. D. (2012). Acceptability and conflict regarding suburban deer management methods. Human Dimensions of Wildlife, 17(6), 389-403. https://doi.org/10.1080/10871209.2012.684196

van Eeden, L. M., Newsome, T. M., Crowther, M. S., Dickman, C. R., \& Bruskotter, J. (2019). Social identity shapes support for management of wildlife and pests. Biological Conservation, 231, 167-173. https://doi.org/10.1016/j.biocon.2019.01.012

van Eeden, L. M., Slagle, K., Newsome, T. M., Crowther, M. S., Dickman, C. R., \& Bruskotter, J. T. (2020). Exploring nationality and social identity to explain attitudes toward conservation actions in the United States and Australia. Conservation Biology, 34(5), 1165-1175. https://doi.org/10.1111/ cobi. 13488

Vaske, J. J. (2019). Survey research and analysis. Sagamore-Venture LLC.

Vaske, J. J., Roemer, J. M., \& Taylor, J. G. (2013). Situational and emotional influences on the acceptability of wolf management actions in the Greater Yellowstone Ecosystem. Wildlife Society Bulletin, 37(1), 122-128. https://doi.org/10.1002/wsb.240

Waldron, A., Mooers, A. O., Miller, D. C., Nibbelink, N., Redding, D., Kuhn, T. S., Roberts, J. T., \& Gittleman, J. L. (2013). Targeting global conservation funding to limit immediate biodiversity declines. Proceedings of the National Academy of Sciences, 110(29), 12144-12148. https://doi.org/ $10.1073 /$ pnas. 1221370110 